\title{
Synergies of Antiangiogenic Therapy and Immune Checkpoint Blockade in Renal Cell Carcinoma: From Theoretical Background to Clinical Reality
}

\author{
Xiaohan Zhou ${ }^{\dagger}$, Wanting Hou ${ }^{\dagger}$, Ling Gao, Lin Shui, Cheng Yi ${ }^{*}$ and Hong Zhu* \\ Department of Medical Oncology, Cancer Center, West China Hospital, Sichuan University, Chengdu, China
}

OPEN ACCESS

Edited by:

Ugo De Giorgi,

Romagnolo Scientific Institute for the

Study and Treatment of Tumors

(IRCCS), Italy

Reviewed by:

Elena Ranieri,

University of Foggia, Italy

Yüksel Ürün,

Ankara University, Turkey

*Correspondence:

Cheng Yi

yicheng6834@163.com

Hong Zhu

441695131@qq.com

tThese authors have contributed equally to this work

Specialty section: This article was submitted to Genitourinary Oncology, a section of the journal Frontiers in Oncology

Received: 27 April 2020 Accepted: 24 June 2020

Published: 29 July 2020

Citation:

Zhou X, Hou W, Gao L, Shui L, Yi C and Zhu H (2020) Synergies of Antiangiogenic Therapy and Immune

Checkpoint Blockade in Renal Cell

Carcinoma: From Theoretical

Background to Clinical Reality.

Front. Oncol. 10:1321.

doi: 10.3389/fonc.2020.01321
The hallmarks of renal cell carcinoma (RCC) are angiogenesis and immunogenic tumor microenvironment. Over the past decades, treatment options for metastatic RCC (mRCC) have been expanding, from the inhibition of vessel formation via antiangiogenic agents (AAs) to the stimulation of immune system by immune checkpoint inhibitors (ICls). Since 2005, the introduction of antiangiogenic agents targeting vascular endothelial growth factor (VEGF), its receptors (VEGFRs), and mammalian target of rapamycin (mTOR) pathway have experienced moderate success in the therapeutics of $\mathrm{mRCC}$, but patient outcomes remain suboptimal. Recently, the development of ICls targeting cytotoxic T-lymphocyte-associated protein 4 (CTLA-4) and the programmed death-1/programmed death ligand 1 (PD-1/PD-L1) pathways has dramatically changed the treatment landscape of mRCC. Expressly, the combination of ipilimumab and nivolumab has been confirmed to improve clinical outcomes and approved as a standard care for intermediate- or poor-risk mRCC patients. Nevertheless, innate or adaptive drug resistance is observed within both treatment approaches, limiting overall clinical benefit. This phenomenon will underscore the urgent need for new combinational therapy strategies with different mechanisms of action, which can improve efficacy in an extended patient population without severe toxic effects. In 2019, as the results of two critical phase III trials came to light, FDA approved axitinib plus avelumab, or pembrolizumab as first-line standard management for mRCC, which cements the combination of AAs plus ICls and advances the mRCC treatment field. This review summarizes current evidence on the interplay and synergies between AAs and immunomodulating drugs in mRCC, focusing on the theoretical background and the status of current clinical development.

Keywords: metastatic renal cell carcinoma, tumor microenvironment, vascular endothelial growth factor (VEGF), antiangiogenic agents, immunotherapy, immune checkpoint inhibitors (ICI), immunomodulation

\section{INTRODUCTION}

Kidney cancer is amid the ten most common cancers in both men and women, with more than 400,000 cases worldwide in 2018 (1). RCC is the predominant type of kidney cancer, and $85 \%$ of RCC is identified as the ccRCC histological subtype (2). In recent years, it was observed that incidence rates of RCC have been climbing. Part of the reason is the incidental detection of renal 
masses during abdominal imaging among higher-income settings. Though most detected tumors are small, the locally advanced disease was still diagnosed in a striking proportion of patients, with up to $17 \%$ of patients initially diagnosed with distant metastases (3). RCC remains a poor prognosis, despite the progress in RCC diagnosis and management over the past two decades. Locally advanced and mRCC have historically been challenging to treat, due to characteristically resistance to standard chemotherapies, radiotherapies, and hormonal therapies, with treatment options traditionally limited (4). Before the development of targeted therapy, cytokine-based (IL-2 and IFN- $\alpha$ ) immunotherapy was approved as the standard care for mRCC, despite the durable long-term responses and prolonged survival in a tiny proportion of patients. These agents bring about significant toxicity by activating the immune system in a non-specific manner, and are unable to identify which patients are likely to respond. Thus, the future widespread use has been precluded (5-7).

As our basic knowledge on RCC tumorigenesis increased, it has translated into the initially successful development and application of targeted agents in RCC management. In particular, VEGF-targeting antiangiogenic agents have been most widely used in the first-line treatment setting. Sorafenib gained FDA approval in 2005, quickly followed by others, including sunitinib, pazopanib, axitinib, and cabozantinib (812). Though antiangiogenic therapy can provide remarkable short-term clinical benefits in objective response rate (ORR) and progression-free survival (PFS), it commonly develops into therapeutic resistance, and hence rarely produce enduring longterm responses or survivals (13).

Based on a deeper understanding of $\mathrm{T}$ cell activation, the establishment of ICI has brought a golden era in mRCC therapeutic landscape $(14,15)$. The two main types of ICIs target CTLA-4 and PD-1/PD-L1 (Figure 1). CTLA-4 is a receptor present on $\mathrm{T}$ cells where it acts as a brake on $\mathrm{T}$ cell activation. Thus, inhibition of CTLA-4 aims at a relief of this kind of obstacle, and allowing the native immune system to instigate antitumor immunity. PD-1 is also present on $\mathrm{T}$ cells, leading to down-regulation of immune responses when bound to its ligand PD-L1. Tumor cells often express PD-L1 to mediate this blockage. Thus, the strategy of inhibiting PD1 or PD-L1 is to prevent this down-regulation of antitumor immunity (16). Nivolumab, a monoclonal antibody targeting PD-1, was the first ICI approved in mRCC treatment, showing longer overall survival (OS) of patients following antiangiogenic therapy, and fewer grade 3 or 4 adverse events occurred compared to everolimus $(17,18)$. Accumulating evidence, however, demonstrates that not all patients may benefit from

\footnotetext{
Abbreviations: AA, Antiangiogenic Agent; CAR-T, Chimeric Antigen Receptor T-Cell; CTLA-4, Cytotoxic T-lymphocyte-Associated Protein 4; DC, Dendritic Cell; ICI, Immune Checkpoint Inhibitors; IMDC, International Metastatic Database Consortium; MDSC, Myeloid-Derived Suppressor Cell; MHC, Major Histocompatibility Complex; ORR, Objective Response Rate; OS, Overall Survival; PD-1/PD-L1, Programmed Death-1/Programmed Death Ligand-1; PFS, Progression-Free Survival; RCC, Renal Cell Carcinoma; TIL, Tumor Infiltrating Lymphocyte; TKI, Tyrosine Kinase Inhibitors; Treg, Regulatory T cell; VEGF, vascular endothelial growth factor.
}

single-agent immunotherapy, underscoring that combination regimens can improve efficacy in broader groups of patients without exacerbating toxic effects (19). Since then, multiple kinds of research that explore various ICI combination regimens have emerged (20).

The combination of nivolumab and ipilimumab was the first step in this direction. In CheckMate 214 (21), a pivotal phase III trial, a combination strategy, nivolumab plus ipilimumab, indicated statistically superior median OS and higher ORR in patients with intermediate- and poor-risk disease by international metastatic database consortium (IMDC) criteria compared with sunitinib, thus leading to the FDA approval as a first-line treatment in 2018.

Current clinical investigations have focused on evaluating combination regimens containing ICIs and VEGFR-directed tyrosine kinase inhibitors (TKIs). Last year, three crucial phase III trials released their preliminary result, and two of them shortly got FDA-approval as standard treatment approaches for mRCC in the first-line setting.

In this review, we discussed the appropriate use of combination therapy (AAs plus ICIs) in mRCC, and purveyed an overview of the mechanisms and preclinical rationale of this strategy, including the potential role that AAs may play on tumor microenvironment and host immunity. The progresses of clinical trials, efficacy evidence and current controversies of combination regimens were summarized and discussed also.

\section{ANGIOGENESIS AND IMMUNE SUPPRESSION IN RCC MICROENVIRONMENT}

ccRCC, the dominant histologic subtype of RCC, is closely associated with mutation or inactivation of the von HippelLindau (VHL), tumor suppressor gene that encodes VHL protein which is a key component of the cellular oxygensensing pathway $(22,23)$. Specifically, VHL protein is a crucial member of the ubiquitin ligase complex which can degrade hypoxia-inducible factor (HIF) subunits HIF$1 \alpha$. When VHL gene is lost or inactivated, HIF-1 $\alpha$ over accumulates. Subsequently, HIF-1 $\alpha$ over-accumulation drives the cellular hypoxic response, resulting in transcription of several target genes involved in angiogenesis, oxygen transport, glucose uptake and metabolism, cell proliferation, and chemotaxis, which leads to carcinogenesis eventually (24-26). Enhanced angiogenesis, therefore, is one of the signatures of clear-cell RCC. Meanwhile, this disbalance of pro- and anti-angiogenic factors brings about numerous structural and functional abnormalities in tumor vessels characterized by irregular shape, tortuousness, hyperpermeability, lack of pericytes. All these changes induce an abnormal blood flow with resultant tumor cell extravasation, $\mathrm{T}$ cell intratumoral infiltration, and altered antitumor agent delivery (27).

On the other hand, it is widely regarded that RCC has a unique immune microenvironment (28). Perhaps more than any other solid tumor type, RCC is infiltrated with 


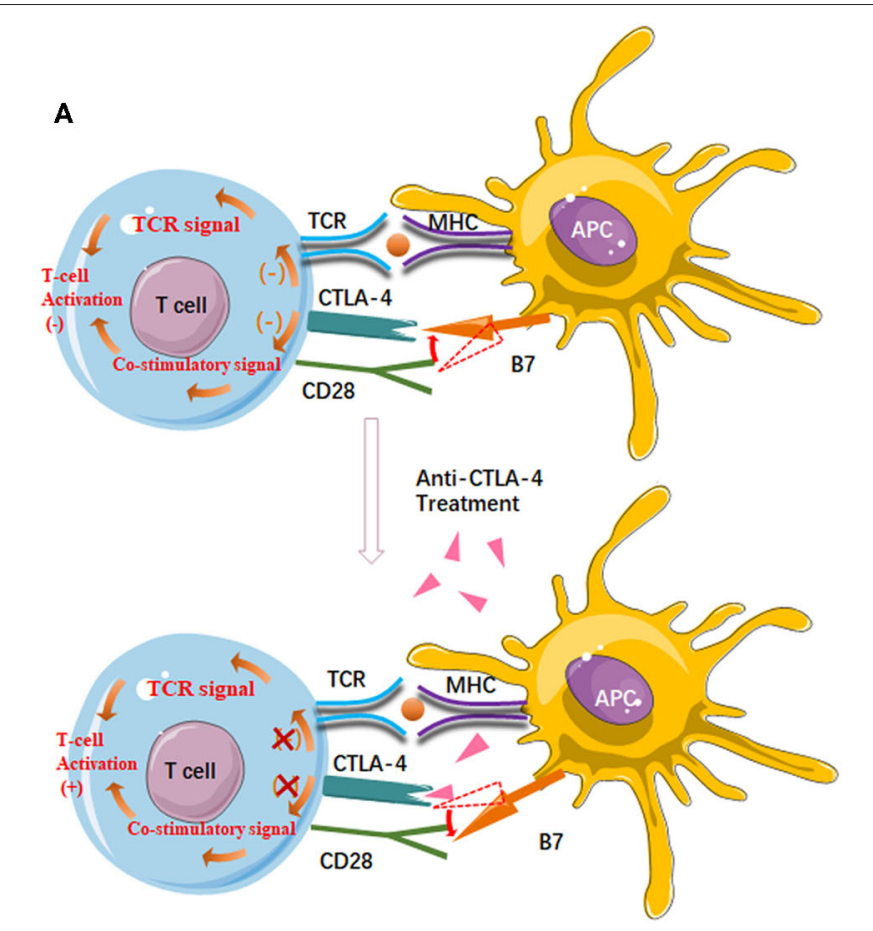

B

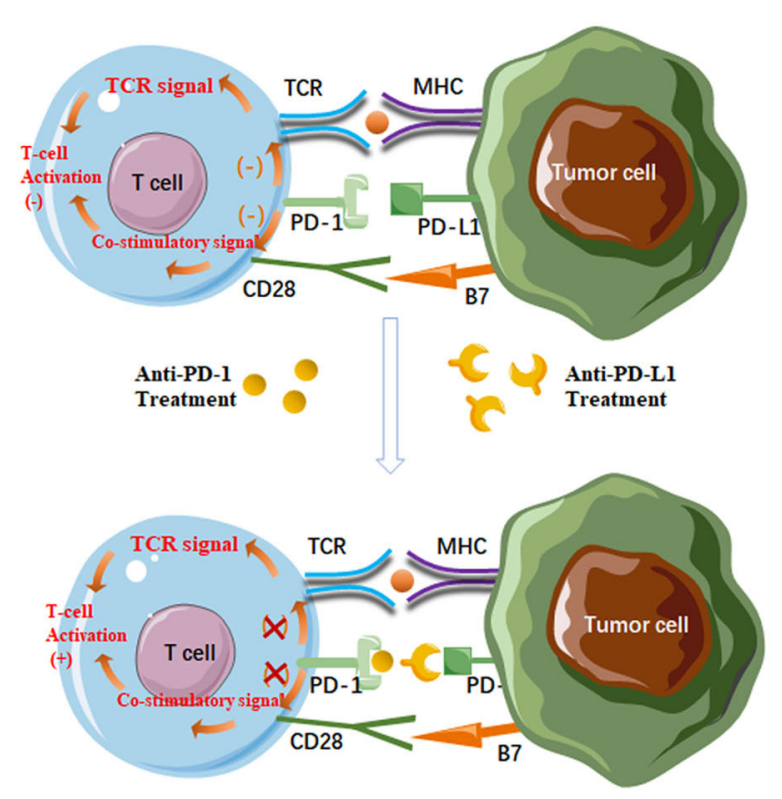

FIGURE 1 | (A) Anti-CTLA-4 agents enhance T cell activation. CTLA-4 has a higher affinity for B7 than CD28. CTLA-4/B7 ligation reduces CD28/B7 ligation and then suppresses T cell activation. On the other hand, the interaction between CTLA-4 and B7 inhibits the stimulatory signals produced by TCR/MHC and CD28/B7 binding. Antibodies targeting CTLA-4 deplete CTLA-4 from the tumor microenvironment and thereby enhance T cell activation; (B) Anti-PD-1/PD-L1 agents enhance the anticancer activity of T cells. PD-1/PD-L1 ligation inhibits T cell activation and TCR signal. Antibodies targeting PD-1 or PD-L1 can block the PD-1/PD-L1 pathway to reactivate tumor antigen recognition as well as the proliferation, infiltration, and activation of cytotoxic CD8 $8^{+} \mathrm{T}$ cells.

immune cells of various phenotype and function $(29,30)$. Mass cytometry has been used to comprehensively described tumor resident $\mathrm{T}$ cell from 73 ccRCC patients with different stages. T cells were the most common immune subset (50\%) followed by tumor-associated macrophages $(25 \%)$, natural killer cells (9\%), B cells (4\%) and other subsets (31). In line with other evidence, tumor-infiltrating $\mathrm{T}$ cells were predominantly $\mathrm{CD} 8^{+}$cells. However, the high levels of $\mathrm{CD}^{+}$ $\mathrm{T}$ cell infiltration in RCC is associated with worse outcome, which is in contrast to most other tumor types, indicating that infiltrating $\mathrm{CD}^{+} \mathrm{T}$ cell pool is probably dominated by nearly exhausted $\mathrm{T}$ cells $(32,33)$. This negative correlation is likely attributed to the high expression of PD-1, CTLA4 , other immune checkpoint proteins on these invading $\mathrm{T}$ cells, and the impaired cytolytic function through interaction with other cells in tumor environment, such as myeloidderived suppressor cells (MDSCs), which proved to suppress T cell and dendritic cell (DC) function (34, 35). Indeed, many studies on RCC microenvironment have reported defective T cell with dysfunctional cytotoxicity and ineffective tumor cell killing (36-39).

Taken together, the TME of RCC features high levels of angiogenic mediators, chemokines, and incapacitated $\mathrm{T}$ cells affected by checkpoint regulation or the immunosuppressive effects of MDSCs.

\section{BIOLOGICAL RATIONALE FOR COMBINED AA AND IMMUNE-ACTIVATING THERAPY}

There is a broad sense that tumor immune evasion closely relates to angiogenesis, and, in turn, tumor angiogenesis highly depends on immunosuppressive microenvironment, which is companion processes in tumorigenesis (Figure 2) (40). Mounting evidence now show that elevated level of VEGF in tumor lesion may cause suppression in both innate and adaptive immune response, and increased serum or tumor VEGF levels are associated with unfavorable prognosis in mRCC patients (41). Reportedly, VEGF can inhibit the innate immune system via hampering the transcriptional program required for maturation of DCs, the critical cells in immune activation, and increasing the presence of MDSCs, which represent a heterogeneous population of cells that accumulate in tumor-bearing hosts, characteristic by their potent immune-suppressive activity against cytotoxic tumorinfiltrating lymphocytes (TIL) (42-45). VEGF also inhibits the adaptive immune system through blocking the differentiation of progenitor cells into $\mathrm{CD} 4^{+}$and $\mathrm{CD} 8^{+} \mathrm{T}$ cells (46). Additionally, potent immunosuppressive factors, like inhibitory molecules on T cells (PD-1) and immunosuppressive cytokines (IL-10, TGF $\beta$ ), are also boosted by HIF- $1 \alpha$ activation (47).

Multiple compelling data with promising insights into the potentiality of AAs, especially targeting VEGFR, as 


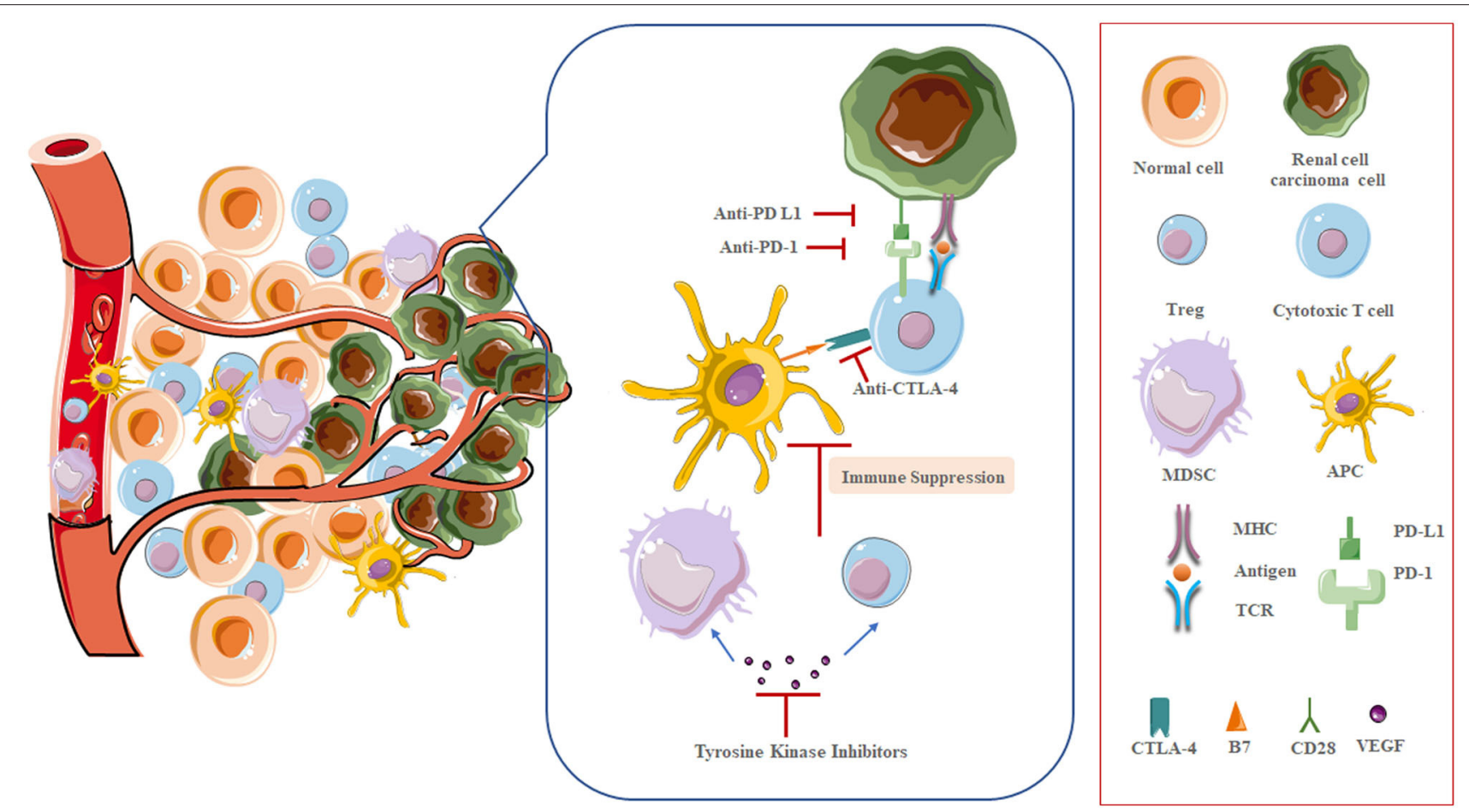

FIGURE 2 | The interplay between the immune system and angiogenesis in renal cell carcinoma.

immunomodulators have been unveiled. Preliminary evidence has indeed demonstrated that anti-angiogenesis, especially targeting VEGF, might reverse the immunosuppression in tumor microenvironment of RCC, potentially promoting the efficacy of subsequent immunotherapy $(48,49)$. Initially, in clinic, the synergy of AA, bevacizumab, plus immunotherapy (IFN- $\alpha$ ), although not by checkpoint inhibitors, has been demonstrated by two large randomized phase III trials in previously untreated mRCC patients, with improved PFS and ORR compared with IFN- $\alpha$ alone, leading to FDA-approval as a first-line treatment option in mRCC $(6,50)$. Permanently discontinued treatment caused by treatment-related adverse events were frequently observed in combined treatment groups.

At present, the development of ICIs provides us a new chance to reconsider the balance between efficacy and toxicity.

A preclinical study in mice reported that tumor-associated VEGF enhanced expression of PD-1 and other inhibitory checkpoints involved in $\mathrm{CD} 8^{+} \mathrm{T}$ cell exhaustion, such as CTLA4, TIM-3, and LAG-3, and targeting VEGF reverted expression of inhibitory checkpoints (51). Similarly, another preclinical mice RCC model showed synergistic antitumor activity of the combination of suntinib plus a murine anti-PD- 1 antibody, with greater numbers of tumor infiltrating lymphocytes than any other controls treated with each agent alone (52). In 2008, for the first time it was shown in $42 \mathrm{mRCC}$ patients, that sunitinib decreased the presence of regulatory T cells (Treg) and MDSCs in the peripheral blood, accompanied by an improved Th1 response and reverses type- 1 immune suppression in $\mathrm{mRCC}$ patients (53). Consistently, in 2009, a study conducted by Ko et al. indicated that sunitinib-based treatment has the potential to regulate antitumor immunity by decreasing the absolute number and percentage of circulating Tregs and MDSCs, demonstrating reversal in immune suppression. In $23 \mathrm{mRCC}$ patients receiving to $50 \mathrm{mg}$ sunitinib daily for 28 days followed by 14 days of rest for 6 weeks (54). Research exploring microenvironmental immune components demonstrated potential synergism of VEGF-TKI and anti-PD-L1 treatment in a neoadjuvant setting (55). The expansion of $\mathrm{CD}^{+}$TIL and reduction in MDSCs were observed in tumor digests from RCC patients who received sunitinib prior to the surgery, compared with those who were treatmentnaïve. These TIL products contained more PD-1 expressing TIL, while the Treg infiltration was not altered. These data provide a rationale for combining sunitinib with PD-1/PD-L1 blockade, either synchronously, or sequentially.

Insight into how different AAs may vary in their competence in regulating TME is still limited. Unlike sunitinib, the detrimental effects of sorafenib on immune-modulating have been reported. This TKI seems to interfere with the progress of maturation and antigen presentation of DCs by downregulating the expression of major histocompatibility complex (MHC) and costimulatory molecules, as well as declining production of immunostimulatory cytokines (56). On the other hand, it was reported that sorafenib could decrease the percentage of circulating and tumor-infiltrating Tregs $(57,58)$, making the immune condition to a more stimulatory setting. 
Regarding pazopanib, it was reported that it could reduce the expression of VEGFR1 and VEGFR2 to offset the immunosuppressive effects of VEGF, which affect DC maturation, and restore property DC immune stimulation by downregulating the Erk/ $\beta$-catenin pathway $(59,60)$.

A small-scale study presented that pazopanib, but not sunitinib, sharply improved the antigen-presenting function of DCs, together with DC-maturation markers HLA-DR, CD40, and CCR7 upregulated, in RCC patients (61). This phenomenon may lie in the diversity of immune regulation effect and a similar pattern of receptor recognition displaying different affinities for VEGFR among agents (62). Besides, pazopanib decreases the absolute number of MDSCs, Tregs and CD14 ${ }^{+}$monocytes and triggers $\mathrm{CD}^{+}$lymphocytes and $\mathrm{T}$ cell memory Th1 response (63). Conflicting data also exist, a multicenter phase II trial showed a clear association between presurgical pazopanib and declined $\mathrm{CD}^{+}{ }^{+} \mathrm{T}$ cell infiltration and increased PD-L1 expression by biomarker analysis from sequential tissue samples (64).

In terms of bevacizumab, data released by Wallin et al. (65) demonstrated that enhanced trafficking of lymphocytes and high $\mathrm{CD}^{+} \mathrm{T}$ cell infiltration had been found after combination therapy of bevacizumab plus atezolizumab in mRCC patients. Concomitantly, a related increase was observed in intra-tumoral major histocompatibility complex-1 (MHC-I) protein expression, Th1 and T-effector markers, and chemokines, especially CX3CL1. More recently, in neoadjuvant treatment, presurgical bevacizumab has been noted to reduce $\mathrm{CD}^{+} 8^{+}$ macrophages in ccRCC patients, preventing macrophages cellmediated immune-suppression (66). Cabozantinib has also been observed to increase intratumoral $\mathrm{CD}^{+}{ }^{+} \mathrm{T}$ cell infiltration, as well as decrease the number and activity of MDSCs infiltration in several preclinical models which designed to explore the effects of cabozantinib on the immune cells function and immune microenvironment $(67,68)$.

\section{CURRENT THERAPEUTIC LANDSCAPE}

A series of clinical trials have been conducted to evaluate the antineoplastic effects of ICIs and AAs combinations. In this review, a systematic study collection was performed from Cochrane Library, ClinicalTrials, MEDLINE and PubMed databases up to April 10th, 2020. Search terms we used included "renal cell carcinoma," "nivolumab," "pembrolizumab," “atezolizumab," “avelumab," "durvalumab," “ipilimumab," or "immune checkpoint inhibitor" with "sunitinib," "axitinib," “cabozantinib," “apatinib," "pazopanib," "lenvatinib," “sorafenib," or "bevacizumab," and related and expanded MeSH terms. Also, we expanded our search to recent reviews. Studies involving concurrent intervention of ICIs and AAs were eligible. The population of interest was patients histologically or cytologically confirmed RCC with clear cell component or sarcomatoid features. Trials were excluded when involving other cancer patients or combining other kind of intervention unless outcome could be isolated.

In 2019, results of two widely anticipated trials were unveiled in the same issue of the New England Journal of Medicine.
KEYNOTE-426 study is an open-label phase III study designed to assess the efficacy and safety of pembrolizumab plus axitinib vs. sunitinib monotherapy in treatment-naïve patients with mRCC (69, 70). After a median follow-up period of 12.8 months, pembrolizumab plus axitinib seemed to be superior to sunitinib only in ORR (59 vs. $35 \%$ ) and mPFS (15.1 vs. 11.1 months; HR = $0.69,95 \%$ CI $0.57-0.84)$ regardless of the risk groups. The most promising data set was the OS: $89 \%$ of combination arm and $78.3 \%$ of sunitinib control arm were alive after 12 -month followup (HR for death, 0.53; 95\% CI 0.38-0.74; $p<0.0001$ ). Toxicities were comparable between the two groups.

In a similarly designed randomized multicenter phase III trial (Javelin Renal 101), 886 enrolled treatment-naïve patients with advanced RCC were assigned to receive either avelumab plus axitinib or sunitinib monotherapy $(n=444)(71)$. The coprimary endpoints were PFS and OS in the PD-L1 positive (PD$\mathrm{L}^{+}$) patients, which occupied $63 \%$ of the randomly selected population. PFS analysis was in favor of the combination regimen for PD-L1+ patients (13.8 vs. 7.2 months; $\mathrm{HR}=0.61,95 \% \mathrm{CI}$ $0.475-0.790)$ and the overall population (13.8 vs. 8.4 months; HR $=0.69,95 \%$ CI $0.563-0.840$ ). The confirmed ORR in avelumab plus axitinib group and sunitinib group was 55.2 vs. $25.5 \%$, respectively, and, above all, the efficacy of combination arms was consistent across the IMDC risk groups. As of the study reported, OS analysis was still immature. Taken together, results from these trials promoted recent FDA approvals of pembrolizumab or avelumab plus axitinib in the first-line management of advanced RCC, cementing the ICIs plus AAs strategy and improving the therapeutic landscape of $\mathrm{mRCC}$.

Another phase III IMmotion151 trial compared the combination of atezolizumab plus bevacizumab to sunitinib as first-line management for mRCC patients (72). In the subset of patients who were PD-L1 ${ }^{+}$interim analysis confirmed that combinational treatment group prolonged PFS (11.2 vs. 7.7 months, HR 0.74; 95\% CI 0.57-0.96) and ORR (43 vs. 35\%), amid whom complete response reached $9 \%$. Meanwhile, patients received atezolizumab plus bevacizumab suffered fewer grade $3 / 4$ adverse events compared to sunitinib only (40 vs. $54 \%$, respectively). Matured OS data are pending, and longer-term follow-up is required to evaluate whether a survival benefit will finally emerge (12).

It is worth mentioning that the tolerability and safety of newer combination regimens should be carefully balanced to that of monotherapies. CheckMate 016 (73) was the first clinical trial to examine the tolerability and safety of combination immunotherapy in advanced RCC. This multicenter phase I study had 5 treatment arms, including the combination of nivolumab with either TKIs, sunitinib, or pazopanib. This combination did exhibit antitumor efficacy. The ORR was $54.5 \%$ in nivolumab plus sunitinib $(\mathrm{N}+\mathrm{S})$ group and $45 \%$ in nivolumab plus pazopanib $(\mathrm{N}+\mathrm{P})$ group, but hepatic and renal toxicity was much higher than expected. Reportedly, all patients assigned to the ICIs plus VEGF-TKIs combination arms experienced treatment-related adverse events, with 81.8 and $70 \%$ of patients developing grade $3-4$ side events, in $\mathrm{N}+\mathrm{S}$ and $\mathrm{N}+\mathrm{P}$ arm, respectively. The most common grade 3-4 adverse events were hypertension, liver enzymes rise, hyponatremia, and 
TABLE 1 | Clinical trials investigating antiangiogenic therapy in combination with immune checkpoint inhibitors in patients with mRCC.

\begin{tabular}{|c|c|c|c|c|c|c|}
\hline $\begin{array}{l}\text { Clinicaltrials gov } \\
\text { number/trial name (if } \\
\text { applicable) }\end{array}$ & Phase & ICls & AAs & $\begin{array}{l}\text { Primary } \\
\text { endpoint }\end{array}$ & $\begin{array}{l}\text { Estimated study } \\
\text { completion date }\end{array}$ & Therapy lines \\
\hline \multirow{2}{*}{ NCT02420821 (IMmotion151) } & & & & PFS & & \\
\hline & & & & PD & & \\
\hline $\begin{array}{l}\text { NCT02853331 } \\
\text { (KEYNOTE-426) }\end{array}$ & III & Pembrolizumab & Axitinib & $\begin{array}{l}\text { PFS } \\
\text { OS }\end{array}$ & 2,022 & First line \\
\hline $\begin{array}{l}\text { NCT02684006 } \\
\text { (JAVELIN Renal 101) }\end{array}$ & III & Avelumab & Axitinib & $\begin{array}{l}\text { OS }\left(\mathrm{PD}-\mathrm{L} 1^{+}\right) \\
\text {PFS }\left(\mathrm{PD}-\mathrm{L} 1^{+}\right)\end{array}$ & 2,024 & First line \\
\hline NCT02811861 (CLEAR) & III & Pembrolizumab & Lenvatinib & PFS & 2,022 & First line \\
\hline NCT03937219 (COSMIC-313) & III & $\begin{array}{l}\text { Nivolumab } \\
\text { ipilimumab }\end{array}$ & Cabozantinib & PFS & 2,024 & First line \\
\hline $\begin{array}{l}\text { NCT03141177 (CheckMate } \\
\text { 9ER) }\end{array}$ & III & Nivolumab & Cabozantinib & PFS & 2,024 & First line \\
\hline \multirow[t]{3}{*}{ NCT02501096 } & $\mathrm{lb} / \mathrm{ll}$ & Pembrolizumab & Lenvatinib & MTD & 2,020 & Second line \\
\hline & & & & DLTs & & \\
\hline & & & & ORR & & \\
\hline NCT03149822 & $1 / 11$ & Pembrolizumab & Cabozantinib & ORR & 2,020 & First line \\
\hline \multirow[t]{2}{*}{ NCT02210117 } & । & Ipilimumab & Bevacizumab & Safety & 2,020 & Neoadjuvant \\
\hline & & & & Tolerability & & \\
\hline NCT03680521 & $\|$ & Nivolumab & Sitravatinib & ORR & 2,020 & First line \\
\hline
\end{tabular}

AAs, Antiangiogenic Agents; ICls, Immune Checkpoint Inhibitors; AEs, Adverse Events; DLTs, Dose-Limiting Toxicities; MTD, Maximum Tolerated Dose; ORR, Objective Response Rate; OS, Overall Survival; PD, Disease Progression; PD-L1+, PD-L1 positive patients; PFS, Progression-Free Survival.

lymphocytopenia. Nearly one-third of patients in both groups permanently discontinued treatment because of treatmentrelated adverse events, although combined therapy brought higher response rates compared to monotherapy. To our knowledge, only one study, a phase I dose-escalation trial, investigated antiangiogenic therapy (sunitinib) in combination with tremelimumab, a monoclonal antibody against CTLA-4. For nine of 21 patients evaluable for response, the ORR was $43 \%$, and disease stabilization was $33 \%$, but due to unexpected and surprising toxicity, like acute renal failure and death, this combination therapeutic strategy was not considered worthy of further exploration (74). Another phase I/II trial (Keynote-018, NCT02014636) examining the combination of pembrolizumab plus pazopanib released its results at the American Society of Clinical Oncology (ASCO) Conference in June 2017. Similarly, these results suggested that this kind of combination is unsafe and reported significant concerns with regard to hepatotoxicity, despite improved response rates (75).

Multiple ongoing and future trials are exploring the role of various drug combinations (Table 1). There are two other keenly anticipated phase III trials in the pipeline, CheckMate 9ER (NCT03141177) and KEYNOTE-581/CLEAR (NCT02811861). As of right now, neither of them has mature data available. CLEAR, a multicenter, open-label, phase III trial has three arms, exploring pembrolizumab plus lenvatinib, or everolimus plus lenvatinib, or sunitinib monotherapy in the first-line mRCC setting. Its preceding phase II study unveiled that combination of pembrolizumab and lenvatinib offered an improved median PFS of 17.7 months as well as an improved ORR of $66.7 \%$ with tolerable toxicity (76). The primary endpoint of this ongoing phase III trial will be PFS with secondary endpoints as OS, ORR, health-related quality of life (HRQoL), and safety profiles and the estimated completion date will be in 2022. CheckMate 9ER, a two-armed phase III randomized study, is assessing nivolumab plus cabozantinib vs. sunitinib monotherapy in 701 previously untreated mRCC patients (77). Revealingly, a phase I trial focusing on the same combination strategy released impressive antitumor efficacy with pretreated mRCC patients enrolled (78). The last ICI and AA combinational regimen brought together pembrolizumab and cabozantinib. Although available data are from the phase I setting, these results are promising with the chance to improve patient care in the future (79). Enrollment of a phase II dose expansion is now ongoing (NCT03149822).

\section{SUMMARY AND FUTURE DIRECTIONS}

The standard of mRCC management has experienced many radical changes over the past decade, and is in a state of revisions 
at present. Although the strategy of combining ICIs with AAs has a strong biological rationale, there is a lack of comparative studies juxtaposing novel combination front-line options, most of the available studies utilizing sunitinib monotherapy as a comparator arm. Taking this into account, the selection of firstline management for patients with mRCC should involve a thorough discussion and a comprehensive comparison of both efficacy and safety of available options.

In addition, rational and prospective trial designs with more extended follow-up period are necessary to figure out the remaining questions related to ICIs plus AAs approaches in mRCC care. Taken together, clinicians will need to confirm whether benefits of these agents are additive or synergistic and whether similar results can be achievable by sequentially using these agents. Clinicians also need to confirm whether the combination approach is always preferred or under what kind of circumstances can monotherapy be better.

Finally, as systemic therapies continue to evolve, it will be paramount to integrate multimodal approaches, including cytoreductive nephrectomy, stereotactic ablative radiotherapy and chimeric antigen receptor $\mathrm{T}$ cell (CAR-T) Immunotherapy, into the current treatment paradigm. For example, it is challenging to maintain peripheral CAR-T cell persistent. Early

\section{REFERENCES}

1. Bray F, Ferlay J, Soerjomataram I, Siegel RL, Torre LA, Jemal A. Global cancer statistics 2018: GLOBOCAN estimates of incidence and mortality worldwide for 36 cancers in 185 countries. CA Cancer J Clin. (2018) 68:394-424. doi: $10.3322 /$ caac. 21492

2. Znaor A, Lortet-Tieulent J, Laversanne M, Jemal A, Bray F. International variations and trends in renal cell carcinoma incidence and mortality. Eur Urol. (2015) 67:519-30. doi: 10.1016/j.eururo.2014.10.002

3. Capitanio U, Montorsi F. Renal cancer. Lancet. (2016) 387:894-906. doi: 10.1016/S0140-6736(15)00046-X

4. Siva S, Kothari G, Muacevic A, Louie AV, Slotman BJ, Teh BS, et al. Radiotherapy for renal cell carcinoma: renaissance of an overlooked approach. Nat Rev Urol. (2017) 14:549-63. doi: 10.1038/nrurol.2017.87

5. Atkins $\mathrm{MB}$, Regan $\mathrm{M}$, McDermott $\mathrm{D}$. Update on the role of interleukin 2 and other cytokines in the treatment of patients with stage IV renal carcinoma. Clin Cancer Res. (2004) 10(Pt. 2):6342-6s. doi: 10.1158/1078-0432.CCR-040029

6. Rini BI, Halabi S, Rosenberg JE, Stadler WM, Vaena DA, Ou SS, et al. Bevacizumab plus interferon alfa compared with interferon alfa monotherapy in patients with metastatic renal cell carcinoma: CALGB 90206. J Clin Oncol. (2008) 26:5422-8. doi: 10.1200/JCO.2008.16.9847

7. Shariat SF, Bolenz C, Karakiewicz PI. Words of wisdom. Re: bevacizumab plus interferon alfa-2a for treatment of metastatic renal cell carcinoma: a randomised, double-blind phase III trial. Eur Urol. (2008) 54:948-9. doi: 10.1016/j.eururo.2008.07.026

8. Motzer RJ, Hutson TE, Tomczak P, Michaelson MD, Bukowski RM, Rixe O, et al. Sunitinib versus interferon alfa in metastatic renal-cell carcinoma. $\mathrm{N} \mathrm{Engl}$ J Med. (2007) 356:115-24. doi: 10.1056/NEJMoa065044

9. Escudier B, Eisen T, Stadler WM, Szczylik C, Oudard S, Staehler M, et al. Sorafenib for treatment of renal cell carcinoma: final efficacy and safety results of the phase III treatment approaches in renal cancer global evaluation trial. $J$ Clin Oncol. (2009) 27:3312-8. doi: 10.1200/JCO.2008.19.5511

10. Sternberg CN, Davis ID, Mardiak J, Szczylik C, Lee E, Wagstaff J, et al. Pazopanib in locally advanced or metastatic renal cell carcinoma: evidence in hematological malignancy models showed that PD1 or PD-L1 might enhance CAR-T persistence (80). Local radiotherapy has also been observed to improve the response to ICI and AA in RCC $(81,82)$. In contrast to the shortage of treatment approaches and overwhelming toxicities before, treating $\mathrm{mRCC}$ is undoubtedly becoming increasingly complex with multiple trials performed and ongoing, and clinicians are faced with daunting challenges of staying abreast of the newest developments and integrating them into the care algorithms.

\section{AUTHOR CONTRIBUTIONS}

$\mathrm{XZ}, \mathrm{WH}$, and HZ: conception and design. CY: administrative support. XZ, WH, LG, and CY: provision of study materials or patients. XZ, WH, LG, and LS: collection and assembly of data. $\mathrm{XZ}$ and WH: manuscript writing. All authors: final approval of manuscript.

\section{ACKNOWLEDGMENTS}

The authors gratefully acknowledge the staff in the Department of Medical Oncology, West China Hospital, Sichuan University and appreciate all the efforts Mr. Yuban Yang have contributed in modifying the language of this article. results of a randomized phase III trial. J Clin Oncol. (2010) 28:1061-8. doi: 10.1200/JCO.2009.23.9764

11. Choueiri TK, Escudier B, Powles T, Mainwaring PN, Rini BI, Donskov F, et al. Cabozantinib versus everolimus in advanced renal-cell carcinoma. $N$ Engl J Med. (2015) 373:1814-23. doi: 10.1056/NEJMoa1510016

12. Rini BI, Powles T, Atkins MB, Escudier B, McDermott DF, Suarez C, et al. Atezolizumab plus bevacizumab versus sunitinib in patients with previously untreated metastatic renal cell carcinoma (IMmotion151): a multicentre, open-label, phase 3, randomised controlled trial. Lancet. (2019) 393:2404-15. doi: 10.1016/S0140-6736(19)30723-8

13. Mantia CM, McDermott DF. Vascular endothelial growth factor and programmed death-1 pathway inhibitors in renal cell carcinoma. Cancer. (2019) 125:4148-57. doi: 10.1002/cncr.32361

14. Tivol EA, Borriello F, Schweitzer AN, Lynch WP, Bluestone JA, Sharpe AH. Loss of CTLA-4 leads to massive lymphoproliferation and fatal multiorgan tissue destruction, revealing a critical negative regulatory role of CTLA-4. Immunity. (1995) 3:541-7. doi: 10.1016/1074-7613(95)90125-6

15. Ribas A, Wolchok JD. Cancer immunotherapy using checkpoint blockade. Science. (2018) 359:1350-5. doi: 10.1126/science.aar4060

16. Pardoll DM. The blockade of immune checkpoints in cancer immunotherapy. Nat Rev Cancer. (2012) 12:252-64. doi: 10.1038/nrc3239

17. Motzer RJ, Escudier B, McDermott DF, George S, Hammers HJ, Srinivas S, et al. Nivolumab versus everolimus in advanced renal-cell carcinoma. $N$ Engl J Med. (2015) 373:1803-13. doi: 10.1056/NEJMoa1510665

18. Mennitto A, Grassi P, Ratta R, Verzoni E, Prisciandaro M, Procopio G. Nivolumab in the treatment of advanced renal cell carcinoma: clinical trial evidence and experience. Ther Adv Urol. (2016) 8:319-26. doi: $10.1177 / 1756287216656811$

19. Tannir N, Hammers H, Amin A. First-line vascular endothelial growth factor targeted therapy in renal cell carcinoma: priming the tumor microenvironment for immunotherapy. Curr Med Res Opin. (2018) 34:82531. doi: $10.1080 / 03007995.2018 .1423960$

20. Hutson TE. Targeted therapies for the treatment of metastatic renal cell carcinoma: clinical evidence. Oncologist. (2011) 16:14-22. doi: 10.1634/theoncologist.2011-S2-14 
21. Cella D, Gruenwald V, Escudier B, Hammers HJ, George S, Nathan P, et al. Patient-reported outcomes of patients with advanced renal cell carcinoma treated with nivolumab plus ipilimumab versus sunitinib (CheckMate 214): a randomised, phase 3 trial. Lancet Oncol. (2019) 20:297-310. doi: 10.1016/S1470-2045(18)30778-2

22. Barry RE, Krek W. The von hippel-lindau tumour suppressor: a multifaceted inhibitor of tumourigenesis. Trends Mol Med. (2004) 10:466-72. doi: 10.1016/j.molmed.2004.07.008

23. Nickerson ML, Jaeger E, Shi Y, Durocher JA, Mahurkar S, Zaridze D, et al. Improved identification of von hippel-lindau gene alterations in clear cell renal tumors. Clin Cancer Res. (2008) 14:4726-34. doi: 10.1158/1078-0432.CCR-07-4921

24. Na X, Wu G, Ryan CK, Schoen SR, Di'Santagnese PA, Messing EM. Overproduction of vascular endothelial growth factor related to von hippellindau tumor suppressor gene mutations and hypoxia-inducible factor1 alpha expression in renal cell carcinomas. J Urol. (2003) 170:588-92. doi: 10.1097/01.ju.0000074870.54671.98

25. Rini BI, Small EJ. Biology and clinical development of vascular endothelial growth factor-targeted therapy in renal cell carcinoma. J Clin Oncol. (2005) 23:1028-43. doi: 10.1200/JCO.2005.01.186

26. Garje R, An JJ, Sanchez K, Greco A, Stolwijk J, Devor E, et al. Current landscape and the potential role of hypoxia-inducible factors and selenium in clear cell renal cell carcinoma treatment. Int J Mol Sci. (2018) 19:3834. doi: 10.3390/ijms19123834

27. Melero I, Rouzaut A, Motz GT, Coukos G. T-cell and NK-cell infiltration into solid tumors: a key limiting factor for efficacious cancer immunotherapy. Cancer Discov. (2014) 4:522-6. doi: 10.1158/2159-8290.CD-13-0985

28. Gigante M, Blasi A, Loverre A, Mancini V, Battaglia M, Selvaggi FP, et al. Dysfunctional DC subsets in RCC patients: ex vivo correction to yield an effective anti-cancer vaccine. Mol Immunol. (2009) 46:893-901. doi: 10.1016/j.molimm.2008.09.015

29. Thompson RH, Dong H, Lohse CM, Leibovich BC, Blute ML, Cheville JC, et al. PD-1 is expressed by tumor-infiltrating immune cells and is associated with poor outcome for patients with renal cell carcinoma. Clin Cancer Res. (2007) 13:1757-61. doi: 10.1158/1078-0432.CCR-06-2599

30. Yoshihara K, Shahmoradgoli M, Martínez E, Vegesna R, Kim H, TorresGarcia W, et al. Inferring tumour purity and stromal and immune cell admixture from expression data. Nat Commun. (2013) 4:2612. doi: $10.1038 /$ ncomms 3612

31. Chevrier S, Levine JH, Zanotelli VRT, Silina K, Schulz D, Bacac M, et al. An immune atlas of clear cell renal cell carcinoma. Cell. (2017) 169:736-49.e718. doi: 10.1016/j.cell.2017.04.016

32. Giraldo NA, Becht E, Pages F, Skliris G, Verkarre V, Vano Y, et al. Orchestration and prognostic significance of immune checkpoints in the microenvironment of primary and metastatic renal cell cancer. Clin Cancer Res. (2015) 21:3031-40. doi: 10.1158/1078-0432.CCR14-2926

33. Siska PJ, Beckermann KE, Mason FM, Andrejeva G, Greenplate AR, Sendor AB, et al. Mitochondrial dysregulation and glycolytic insufficiency functionally impair CD8 T cells infiltrating human renal cell carcinoma. JCI Insight. (2017) 2:e93411. doi: 10.1172/jci.insight.93411

34. Gigante M, Pontrelli P, Herr W, Gigante M, D'Avenia M, Zaza G, et al. miR$29 \mathrm{~b}$ and miR-198 overexpression in CD8 $+\mathrm{T}$ cells of renal cell carcinoma patients down-modulates JAK3 and MCL-1 leading to immune dysfunction. $J$ Transl Med. (2016) 14:84. doi: 10.1186/s12967-016-0841-9

35. Najjar YG, Rayman P, Jia X, Pavicic PG, Rini BI, Tannenbaum C, et al. Myeloid-derived suppressor cell subset accumulation in renal cell carcinoma parenchyma is associated with intratumoral expression of IL1 beta, IL8, CXCL5, and Mip-1 alpha. Clin Cancer Res. (2017) 23:2346-55. doi: 10.1158/1078-0432.CCR-15-1823

36. Gigante M, Mandic M, Wesa AK, Cavalcanti E, Dambrosio M, Mancini V, et al. Interferon-alpha (IFN-alpha)-conditioned DC preferentially stimulate type-1 and limit treg-type in vitro T-cell responses from RCC patients. $J$ Immunother. (2008) 31:254-62. doi: 10.1097/CJI.0b013e318167b023

37. Xin H, Zhang CY, Herrmann A, Du Y, Figlin R, Yu H. Sunitinib inhibition of stat3 induces renal cell carcinoma tumor cell apoptosis and reduces immunosuppressive cells. Cancer Res. (2009) 69:2506-13. doi: 10.1158/0008-5472.CAN-08-4323
38. Taube JM, Klein A, Brahmer JR, Xu HY, Pan XY, Kim JH, et al. Association of PD-1, PD-1 ligands, and other features of the tumor immune microenvironment with response to anti-PD-1 therapy. Clin Cancer Res. (2014) 20:5064-74. doi: 10.1158/1078-0432.CCR-13-3271

39. Mier JW. The tumor microenvironment in renal cell cancer. Curr Opin Oncol. (2019) 31:194-9. doi: 10.1097/CCO.0000000000000512

40. Motz GT, Coukos G. The parallel lives of angiogenesis and immunosuppression: cancer and other tales. Nat Rev Immunol. (2011) 11:702-11. doi: 10.1038/nri3064

41. Shen H, Liu Q, Li M, Yang P. The prognostic value of vascular endothelial growth factor in patients with renal cell carcinoma: a systematic review of the literature and meta-analysis. Clin Invest Med. (2017) 40:E40-8. doi: $10.25011 /$ cim.v40i2.28194

42. Gabrilovich DI, Chen HL, Girgis KR, Cunningham HT, Meny GM, Nadaf $\mathrm{S}$, et al. Production of vascular endothelial growth factor by human tumors inhibits the functional maturation of dendritic cells. Nat Med. (1996) 2:1096103. doi: $10.1038 / \mathrm{nm} 1096-1096$

43. Kusmartsev S, Gabrilovich DI. Role of immature myeloid cells in mechanisms of immune evasion in cancer. Cancer Immunol Immunother. (2006) 55:23745. doi: 10.1007/s00262-005-0048-Z

44. Huang Y, Chen X, Dikov MM, Novitskiy SV, Mosse CA, Yang L, et al. Distinct roles of VEGFR-1 and VEGFR-2 in the aberrant hematopoiesis associated with elevated levels of VEGF. Blood. (2007) 110:624-31. doi: 10.1182/blood-2007-01-065714

45. Alfaro C, Suarez N, Gonzalez A, Solano S, Erro L, Dubrot J, et al. Influence of bevacizumab, sunitinib and sorafenib as single agents or in combination on the inhibitory effects of VEGF on human dendritic cell differentiation from monocytes. Br J Cancer. (2009) 100:1111-9. doi: 10.1038/sj.bjc.6604965

46. Ohm JE, Gabrilovich DI, Sempowski GD, Kisseleva E, Parman KS, Nadaf S, et al. VEGF inhibits T-cell development and may contribute to tumor-induced immune suppression. Blood. (2003) 101:4878-86. doi: 10.1182/blood-2002-07-1956

47. Tartour E, Pere H, Maillere B, Terme M, Merillon N, Taieb J, et al. Angiogenesis and immunity: a bidirectional link potentially relevant for the monitoring of antiangiogenic therapy and the development of novel therapeutic combination with immunotherapy. Cancer Metastasis Rev. (2011) 30:83-95. doi: 10.1007/s10555-011-9281-4

48. Santoni M, Rizzo M, Burattini L, Farfariello V, Berardi R, Santoni G, et al. Present and future of tyrosine kinase inhibitors in renal cell carcinoma: analysis of hematologic toxicity. Recent Pat Antiinfect Drug Discov. (2012) 7:104-10. doi: 10.2174/157489112801619719

49. Heidegger I, Pircher A, Pichler R. Targeting the tumor microenvironment in renal cell cancer biology and therapy. Front Oncol. (2019) 9:490. doi: 10.3389 /fonc. 2019.00490

50. Escudier B, Pluzanska A, Koralewski P, Ravaud A, Bracarda S, Szczylik C, et al. Bevacizumab plus interferon alfa-2a for treatment of metastatic renal cell carcinoma: a randomised, double-blind phase III trial. Lancet. (2007) 370:2103-11. doi: 10.1016/S0140-6736(07)61904-7

51. Voron T, Colussi O, Marcheteau E, Pernot S, Nizard M, Pointet AL, et al VEGF-A modulates expression of inhibitory checkpoints on CD8+ T cells in tumors. J Exp Med. (2015) 212:139-48. doi: 10.1084/jem.20140559

52. Masters G, Dito G, Penhallow B, Lewin A, Kao H, Jure-Kunkel MN Antitumor activity of anti-PD-1 in combination with tyrosine kinase inhibitors in a preclinical renal cell carcinoma model. Cancer Res. (2014) 74:5016. doi: 10.1158/1538-7445.AM2014-5016

53. Finke JH, Rini B, Ireland J, Rayman P, Richmond A, Golshayan A, et al Sunitinib reverses type- 1 immune suppression and decreases T-regulatory cells in renal cell carcinoma patients. Clin Cancer Res. (2008) 14:6674-82. doi: 10.1158/1078-0432.CCR-07-5212

54. Ko JS, Zea AH, Rini BI, Ireland JL, Elson P, Cohen P, et al. Sunitinib mediates reversal of myeloid-derived suppressor cell accumulation in renal cell carcinoma patients. Clin Cancer Res. (2009) 15:2148-57. doi: 10.1158/1078-0432.CCR-08-1332

55. Guislain A, Gadiot J, Kaiser A, Jordanova ES, Broeks A, Sanders J, et al. Sunitinib pretreatment improves tumor-infiltrating lymphocyte expansion by reduction in intratumoral content of myeloid-derived suppressor cells in human renal cell carcinoma. Cancer Immunol. Immunother. (2015) 64:124150. doi: $10.1007 / \mathrm{s} 00262-015-1735-\mathrm{z}$ 
56. Hipp MM, Hilf N, Walter S, Werth D, Brauer KM, Radsak MP, et al. Sorafenib, but not sunitinib, affects function of dendritic cells and induction of primary immune responses. Blood. (2008) 111:5610-20. doi: 10.1182/blood-2007-02-075945

57. Busse A, Asemissen AM, Nonnenmacher A, Braun F, Ochsenreither S, Stather $D$, et al. Immunomodulatory effects of sorafenib on peripheral immune effector cells in metastatic renal cell carcinoma. Eur J Cancer. (2011) 47:690-6. doi: 10.1016/j.ejca.2010.11.021

58. Desar IM, Jacobs JH, Hulsbergen-vandeKaa CA, Oyen WJ, Mulders PF, van der Graaf WT, et al. Sorafenib reduces the percentage of tumour infiltrating regulatory $\mathrm{T}$ cells in renal cell carcinoma patients. Int J Cancer. (2011) 129:507-12. doi: 10.1002/ijc.25674

59. Dikov MM, Ohm JE, Ray N, Tchekneva EE, Burlison J, Moghanaki D, et al. Differential roles of vascular endothelial growth factor receptors 1 and 2 in dendritic cell differentiation. J Immunol. (2005) 174:215-22. doi: 10.4049/jimmunol.174.1.215

60. Zizzari IG, Napoletano C, Botticelli A, Caponnetto S, Calabrò F, Gelibter $A$, et al. TK inhibitor pazopanib primes DCs by downregulation of the $\beta$-catenin pathway. Cancer Immunol Res. (2018) 6:711-22. doi: 10.1158/2326-6066.CIR-17-0594

61. Nuti M, Zizzari I, Napoletano C, Botticelli A, Calabro F, Gelibter A, et al. Immunomodulatory effects of tyrosine kinase inhibitors (TKIs) in renal cell carcinoma (RCC) patients. J Clin Oncol. (2017) 35:e14506. doi: 10.1200/JCO.2017.35.15_suppl.e14506

62. Kumar R, Crouthamel MC, Rominger DH, Gontarek RR, Tummino PJ, Levin RA, et al. Myelosuppression and kinase selectivity of multikinase angiogenesis inhibitors. Br J Cancer. (2009) 101:1717-23. doi: 10.1038/sj.bjc.6605366

63. Fogli S, Porta C, Del Re M, Crucitta S, Gianfilippo G, Danesi R, et al. Optimizing treatment of renal cell carcinoma with VEGFR-TKIs: a comparison of clinical pharmacology and drug-drug interactions of anti-angiogenic drugs. Cancer Treat Rev. (2020) 84:101966. doi: 10.1016/j.ctrv.2020.101966

64. Powles T, Sarwar N, Stockdale A, Sarker SJ, Boleti E, Protheroe A, et al. Safety and efficacy of pazopanib therapy prior to planned nephrectomy in metastatic clear cell renal cancer. JAMA Oncol. (2016) 2:1303-9. doi: 10.1001/jamaoncol.2016.1197

65. Wallin JJ, Bendell JC, Funke R, Sznol M, Korski K, Jones S, et al. Atezolizumab in combination with bevacizumab enhances antigen-specific T-cell migration in metastatic renal cell carcinoma. Nat Commun. (2016) 7:12624. doi: $10.1038 /$ ncomms 12624

66. Tamma R, Rutigliano M, Lucarelli G, Annese T, Ruggieri S, Cascardi E, et al. Microvascular density, macrophages, and mast cells in human clear cell renal carcinoma with and without bevacizumab treatment. Urol Oncol. (2019) 37:355.e311-55.e9. doi: 10.1016/j.urolonc.2019. 01.025

67. Kwilas AR, Ardiani A, Donahue RN, Aftab DT, Hodge JW. Dual effects of a targeted small-molecule inhibitor (cabozantinib) on immune-mediated killing of tumor cells and immune tumor microenvironment permissiveness when combined with a cancer vaccine. J Transl Med. (2014) 12:294. doi: 10.1186/s12967-014-0294-y

68. Lu X, Horner JW, Paul E, Shang X, Troncoso P, Deng P, et al. Effective combinatorial immunotherapy for castration-resistant prostate cancer. Nature. (2017) 545:116. doi: 10.1038/nature22348

69. Atkins MB, Plimack ER, Puzanov I, Fishman MN, McDermott DF, Cho DC, et al. Axitinib in combination with pembrolizumab in patients with advanced renal cell cancer: a non-randomised, open-label, dosefinding, and dose-expansion phase 1b trial. Lancet Oncol. (2018) 19:405-15. doi: 10.1016/S1470-2045(18)30081-0

70. Rini BI, Plimack ER, Stus V, Gafanov R, Hawkins R, Nosov D, et al. Pembrolizumab plus axitinib versus sunitinib for advanced renal-cell carcinoma. N Engl J Med. (2019) 380:1116-27. doi: 10.1056/NEJMoa18 16714
71. Motzer RJ, Penkov K, Haanen J, Rini B, Albiges L, Campbell MT, et al. Avelumab plus axitinib versus sunitinib for advanced renal-cell carcinoma. $N$ Engl J Med. (2019) 380:1103-15. doi: 10.1056/NEJMoa1816047

72. Motzer RJ, Powles T, Atkins MB, Escudier B, McDermott DF, Suarez C, et al. IMmotion151: a randomized phase III study of atezolizumab plus bevacizumab vs sunitinib in untreated metastatic renal cell carcinoma (mRCC). J Clin Oncol. (2018) 36:578. doi: 10.1200/JCO.2018.36.6_suppl.578

73. Amin A, Plimack ER, Infante JR, Ernstoff MS, Rini BI, McDermott DF, et al. Nivolumab (anti-PD-1; BMS-936558, ONO-4538) in combination with sunitinib or pazopanib in patients (pts) with metastatic renal cell carcinoma (mRCC). JClin Oncol. (2014) 32:5010. doi: 10.1200/jco.2014.32.15_suppl.5010

74. Rini BI, Stein M, Shannon P, Eddy S, Tyler A, Stephenson JJ Jr., et al. Phase 1 dose-escalation trial of tremelimumab plus sunitinib in patients with metastatic renal cell carcinoma. Cancer. (2011) 117:758-67. doi: $10.1002 /$ cncr.25639

75. Chowdhury S, McDermott DF, Voss MH, Hawkins RE, Aimone P, Voi $M$, et al. A phase I/II study to assess the safety and efficacy of pazopanib (PAZ) and pembrolizumab (PEM) in patients (pts) with advanced renal cell carcinoma (aRCC). J Clin Oncol. (2017) 35:4506. doi: 10.1200/JCO.2017.35.15_suppl.4506

76. Lee CH, Makker V, Rasco DW, Taylor MH, Stepan DE, Shumaker RC. Lenvatinib plus pembrolizumab in patients with renal cell carcinoma: updated results. J Clin Oncol. (2018) 36:4560. doi: 10.1200/JCO.2018.36.15_suppl.4560

77. Choueiri TK, Apolo AB, Powles T, Escudier B, Aren OR, Shah A. A phase 3, randomized, open-label study of nivolumab combined with cabozantinib vs sunitinib in patients with previously untreated advanced or metastatic renal cell carcinoma (RCC; CheckMate 9ER). J Clin Oncol. (2018) 36:TPS4598. doi: 10.1200/JCO.2018.36.15_suppl.TPS4598

78. Nadal RM, Mortazavi A, Stein M, Pal SK, Davarpanah NN, Parnes HL, et al. Results of phase I plus expansion cohorts of cabozantinib (Cabo) plus nivolumab (Nivo) and CaboNivo plus ipilimumab (Ipi) in patients (pts) with with metastatic urothelial carcinoma (mUC) and other genitourinary (GU) malignancies. J Clin Oncol. (2018) 36:515. doi: 10.1200/JCO.2018.36.6_suppl.515

79. Keeler ME, Kessler ER, Bernard B, Weisdack S, Breaker KM, Wold M, et al. Pembrolizumab (pembro) and cabozantinib (cabo) in patients (pts) with metastatic renal cell carcinoma (mRCC): phase I results. J Clin Oncol. (2019) 37:600. doi: 10.1200/JCO.2019.37.7_suppl.600

80. Chong EA, Melenhorst JJ, Lacey SF, Ambrose DE, Gonzalez V, Levine $\mathrm{BL}$, et al. PD-1 blockade modulates chimeric antigen receptor (CAR)modified T cells: refueling the CAR. Blood. (2017) 129:1039-41. doi: 10.1182/blood-2016-09-738245

81. Wersäll PJ, Blomgren H, Pisa P, Lax I, Kälkner KM, Svedman C. Regression of non-irradiated metastases after extracranial stereotactic radiotherapy in metastatic renal cell carcinoma. Acta Oncol. (2006) 45:493-7. doi: 10.1080/02841860600604611

82. Poleszczuk JT, Luddy KA, Prokopiou S, Robertson-Tessi M, Moros EG, Fishman M, et al. Abscopal benefits of localized radiotherapy depend on activated T-cell trafficking and distribution between metastatic lesions. Cancer Res. (2016) 76:1009-18. doi: 10.1158/0008-5472.CAN-15-1423

Conflict of Interest: The authors declare that the research was conducted in the absence of any commercial or financial relationships that could be construed as a potential conflict of interest.

Copyright $\odot 2020$ Zhou, Hou, Gao, Shui, Yi and Zhu. This is an open-access article distributed under the terms of the Creative Commons Attribution License (CC BY). The use, distribution or reproduction in other forums is permitted, provided the original author(s) and the copyright owner(s) are credited and that the original publication in this journal is cited, in accordance with accepted academic practice. No use, distribution or reproduction is permitted which does not comply with these terms. 